TI 2001- 005/3

Tinbergen Institute Discussion Paper

\title{
A Multicriteria Decision Support Methodology for Evaluating Airport Expansion Plans
}

Ron Vreeker

Peter Nijkamp

Chris Ter Welle 


\section{Tinbergen Institute}

The Tinbergen Institute is the institute for economic research of the Erasmus Universiteit Rotterdam, Universiteit van Amsterdam and Vrije Universiteit Amsterdam.

\section{Tinbergen Institute Amsterdam}

Keizersgracht 482

1017 EG Amsterdam

The Netherlands

Tel.: $\quad+31 .(0) 20.5513500$

Fax: $\quad+31 .(0) 20.5513555$

\section{Tinbergen Institute Rotterdam}

Burg. Oudlaan 50

3062 PA Rotterdam

The Netherlands

Tel.: $\quad+31 .(0) 10.4088900$

Fax: $\quad+31 .(0) 10.4089031$

Most recent TI discussion papers can be downloaded at http:// www.tinbergen.nl 


\title{
A Multicriteria Decision SuPPORT METHOdology FOR Evaluating Airport Expansion Plans
}

\section{9-1-01}

\author{
Ron Vreeker \\ Peter Nijkamp \\ Chris Ter Welle \\ Department of Spatial Economics \\ Free University Amsterdam \\ De Boelelaan 1105 \\ $1081 \mathrm{HV}$ Amsterdam \\ The Netherlands \\ Phone: +31-20-4446088 \\ Fax: +31-20-4446004 \\ Email: rvreeker@econ.vu.nl
}




\section{Table of Contents}

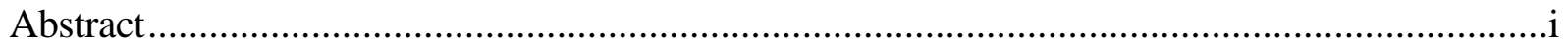

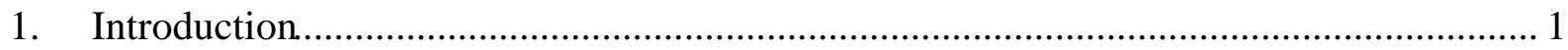

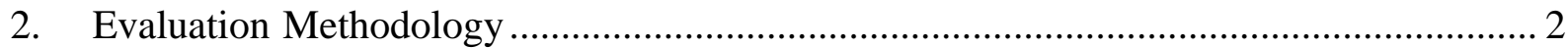

3. The Evaluation Methods Used: A Description...................................................... 7

3.1 The Flag Model............................................................................................ 7

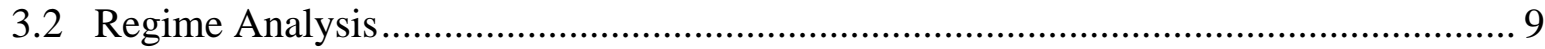

3.3 Saaty's Analytical Hierarchical Process method (AHP) ........................................ 11

4. Application of the Evaluation Methodology and Methods........................................... 12

4.1 Maastricht Aachen Airport (MAA): a short description.......................................... 12

4.2 Hierarchical definition of criteria and assembling the impact matrix ........................ 14

4.3 Regime Analysis; obtaining a rank order of alternatives........................................ 16

4.4 Acceptability of alternatives; application of the Flag Model.................................. 17

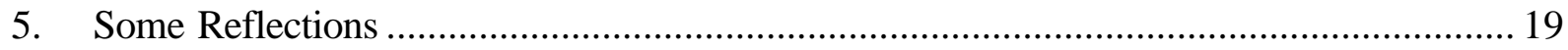

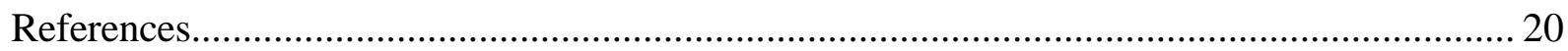




\title{
A MULTICRITERIA DECISION SUPPORT METHODOLOGY FOR EVALUATING AIRPORT EXPANSION PLANS
}

Peter Nijkamp

Ron Vreeker

Chris ter Welle

\begin{abstract}
Rational decision-making requires an assessment of advantages and disadvantages of choice possibilities, including non-market effects (such as externalities). This also applies to strategic decision-making in the transport sector (including aviation). In the past decades various decision support and evaluation methods have been developed in which a market evaluation played a prominent role. The intrinsic limitations of these approaches were also increasingly recognised.

Gradually, a variety of adjusted multidimensional methods has been developed over the past years to complement conventional Cost-Benefit Analysis. These methods aim to investigate and evaluate all relevant impacts of a choice possibility (e.g., project, plan, or programme) on the basis of a multitude of important policy criteria (so-called multicriteria methods). They have a particular relevance in case of non-priced or qualitative effects.

There is a clear need for a systematic and polyvalent multicriteria approach to many actual planning issues, such as land use or transportation. This paper offers a new evaluation framework based on a blend of three types of approaches, viz. Regime Analysis (an advanced pairwise comparison method), the Saaty method (an analytical hierarchical procedure for preference statements) and the Flag Model (based on critical threshold value analysis). All these methods have been developed separately in the past; the paper makes an effort to offer a cohesive framework, which can be used for the evaluation of spatial-economic and environmental-economic policy issues.

This new tool is tested by means of a case study on conflicting plans (and policy views) for airport expansion options in the Maastricht area in the Southern part of the Netherlands.
\end{abstract}




\section{Introduction}

Economic developments are not solely the result of a proper combination of production factors such as labour, land and capital, but also a consequence of a balanced use of overhead capital in general and infrastructure (transport systems and related policies) in particular (Rietveld and Bruinsma, 1999). There is quite some evidence that improving transport systems tends to lead to a higher productivity rate of private production factors.

Beside a static reallocation effect, a major dynamic driving force of economic adjustment is that investments in transport infrastructure and an implementation of efficiency-enhancing transport policies lead to changes in transportation costs (see Nijkamp and Blaas, 1996). These may affect trade relationships and hence also the location of production factors (see Fujita et al., 1999).

The complexity of transport-land use interactions prompts the need for sophisticated assessment methods and clear decision-making processes in order to assess all advantages and disadvantages of choice possibilities at the edge of infrastructure and sustainable land use.

In modern evaluation theory we witness an increasing emphasis on analytical decision support methods. After the popularity of Cost-Benefit Analysis and related financialeconomic evaluation methods (such as cost-effectiveness analysis) we have seen an increasing popularity and widespread use of multicriteria methods. Such methods are capable of dealing with the multiple dimensions of evaluation problems (e.g. social, cultural, ecological, technological, institutional, etc.) and give due attention to interest conflicts among stakeholders involved. In general, the aim of these methods is to combine assessment methods with judgement methods and to offer a solid analytical basis for modern decision analysis (see for a general overview Nijkamp et al., 1990).

The focus of this paper concerns the foundation of these modern assessment methods. It aims to highlight their relevance for strategic transport decision-making from an operational perspective. From the large set of existing and recently developed evaluation methods, three frequently employed assessment techniques (viz. Regime Analysis, the Saaty method and the Flag Model) have been selected for a more thorough treatment. Each of these assessment techniques has a great potential for policy analysis in the transport sector and builds on the foundation of conventional Cost-Benefit Analysis. The presentation of these methods follows a systematic framework set out by a newly developed coherent evaluation methodology. Besides, the functioning of the various methods is clarified by means of a case study on airport expansion in one of the Southern provinces in The Netherlands.

The paper is organised as follows. Section 2 of the paper offers a description of the evaluation methodology. It provides a framework for evaluating transport policies and infrastructure investments in a multidimensional way. Section 3 is dedicated to the three methods included in our methodology. It takes a closer look at the principles of this methodology by means of a more detailed description of the various methods. Section 4 is concerned with the aviation case study; it clarifies the methodology and describes the results

of the application of the evaluation techniques employed. In section 5 we draw conclusions and offer some further reflections. 


\section{Evaluation Methodology}

The standard framework for evaluating transport policies and infrastructure investments from an economic perspective is Cost-Benefit Analysis (CBA). CBA has already a long history in the evaluation of infrastructure projects.

The French engineer Dupuit has laid the theoretical basis for CBA many years' back, in 1844. Dupuit introduced in his article the concept of a consumer's surplus, which has ever since played a crucial role in applied welfare theory (we refer here inter alia to Marshall, Pigou, Keynes, Hicks, Wicksell and Samuelson).

In the second part of the twentieth century, CBA has become increasingly popular as a meaningful and practical evaluation technique for (public) projects. A CBA is originally a capital budgeting system primarily concerned with public projects. CBA is essentially not purely an accounting system, but an evaluation method based on applied welfare theory. It is a method to determine the net social surplus of public investments or of institutional decisions (Mishan, 1971).

If a choice has to be made by public authorities among alternative goods in order to achieve allocative efficiency, the criterion of a maximum willingness to pay has to be used. In this way, CBA can be employed as a monetary evaluation method for assessing the net (social) benefits of (public) projects (Layard, 1997). Clearly, right economic decisions can only be taken when the price system reflects the social revenues and sacrifices in an adequate manner. An essential problem in applying a CBA is indeed the determination of consistent and reliable values of project outcomes (particularly, if the market mechanism does not provide this price system).

A CBA represents thus a systematic enumeration and evaluation of all relevant (i.e. direct and indirect) (social) revenues and costs of a given set of choice possibilities. This analysis incorporates two important stages, viz. impact analysis and monetary assessment. After the execution of these steps the most favourable plan - at least from an economic perspective can be identified in a straightforward way.

Unfortunately, in the history of application of CBA sometimes many intrinsic shortcomings and practical limitations of this evaluation approach have been overlooked. Therefore, it may be useful to examine in slightly more detail some important aspects of CBA.

Accuracy of information. In general, it will be very difficult to assess in an accurate manner all direct and indirect impacts of an infrastructure plan over a long time horizon (for example, the long-term effect of infrastructure on biodiversity).

Distributional equity. In general, distributional effects are omitted in many evaluations, because the judgement of these effects is considered to be politically instigated. However, it has to be noted that distributional effects can in principle be taken into account by employing the notion of compensatory payments (e.g., Hicks-Kaldor compensation test) or attaining a Pareto-equilibrium.

Compensatory payments. A decline in utility of several individuals or groups can be assessed by means of a monetary amount that compensates this decline. The notion of compensation is a direct implication of welfare theory, but its precise amount is in general very hard to operationalise (due to lack of information on preference curves of individuals or a 
society at large). Furthermore, compensatory payments are frequently only introduced as fictitious payments to assess social costs; they are not meant to be out-of-pocket costs.

Discount rate. The time preference of plan impacts is reflected by the (social) rate of discount, but an operational determination of this parameter is very difficult. The value of a (social) discount rate is not an unambiguous parameter, but is essentially the result of a sociopolitical decision. This also explains the variety in values of the social rate of discount.

Lifetime of the project. The lifetime of a transportation project is sometimes hard to assess, as this is not only a technological issue, but also dependent on the emergence of alternative competing projects.

On the basis of the foregoing remarks, the conclusion can be drawn that CBA may, in principle, be a sound evaluation method for decisions in the public sector. It should be noted however, that several severe limitations do exist. As a consequence, also several complementary approaches have been deployed in the past decades, such as cost-effectiveness analysis, planning balance sheet methods and shadow project approaches; they all belong to the same family.

In the recent evaluation history a closer orientation towards actual decision-making processes can be observed, which means that - next to a monetary CBA-based approach - also complementary - in particular decision-making based and institutionally-based - approaches have been deployed. In fact, nowadays one may distinguish at least four types of evaluation styles in the planning literature:

1. a monetary decision approach, based e.g., on Cost-Benefit or cost-effectiveness principles;

2. a utility theory approach, based on prior ranking of the decision-makers' preferences using multicriteria analysis;

3. a learning approach, based on a sequential (interactive or cyclical) articulation of the decision-maker's views;

4. a collective decision approach, based on multi-person bargaining, negotiation or voting procedures.

Information uncertainty and conflict management are thus critical issues. Many conflicting views may emerge in evaluating alternative plans. Especially modern approaches like multicriteria analysis may serve as a meaningful evaluation vehicle for taking explicitly account of such conflicts regarding the foreseeable impacts of a plan (Nijkamp et al., 1990). For example, everybody may agree on the fact that the expansion of an airport will destroy $\mathrm{x}$ hectares of the forest. Multicriteria analysis may then be helpful in taking into account such conflicting issues by considering priority schemes or weights as an ingredient in an evaluation analysis for investment projects. Of course, this will not always lead to a unique final solution, but the structure and consequences of conflicts among decision-makers can be made more explicit, so that also the range of politically feasible alternatives can be analysed in greater detail (see for an overview of evaluation procedures and methods related to infrastructure investments Rietveld, 2000, De Brucker 2000 and Rietveld and Rouwendal, 2000). 
In general, one may argue that the efficiency test on an investment decision can most properly be carried out by means of CBA methods, while equity and sustainability checks need broader approaches based on MCA approaches. In addition, in case of 'soft' information (e.g. ordinal) the latter class of methods is also very suitable (see for example van Pelt, 1994). Thus, we are essentially seeking for the most appropriate decision support method in case of a complex evaluation problem.

To conclude, there is clearly no single assessment and evaluation method that can satisfactorily and unequivocally evaluate all complex aspects of choice possibilities. The choice of assessment methods in any given choice context therefore depends on the features of the problem at hand, on the aims of the analysis, and on the underlying information base. The proposed evaluation methodology gives insight into the above-mentioned aspects that determine the choice of the appropriate evaluation method or combination of evaluation methods. By means of systematically structuring the evaluation process, the methodology ensures the compatibility between the assessment method(s) used and the actual problem to be tackled.

The evaluation methodology proposed and deployed here is based on a blend of three multicriteria evaluation methods. The core of the methodology is formed by Regime Analysis; this pairwise comparison method is extended with two complementary methods, notably the Flag Model and Saaty's Analytic Hierarchical Process (AHP) (see Figure 1). Due to the assessment of impacts in qualitative terms Cost-Benefit Analysis is inappropriate for the decision-making procedure in our case study. Therefore we have to rely on multicriteria analysis, in this case Regime Analysis. Since the plan impacts are all measured in qualitative terms we can not use quantitative weights or preference statements in our analysis. Saaty's Analytic Hierarchical Process is used in order to overcome this problem. By mean of this method ordinal preference statements are transformed into metric (cardinal) data and used in the multicriteria analysis. The existence of development constraints and so-called reference values makes it necessary to deploy an assessment technique that is capable to carry out such a kind of analysis. The Flag Model is able of analysing policy alternatives in the light of $a$

priori defined set of constraints. A concise description of the above-mentioned methods can be found in Section 3.

\section{Step 1. Specification of choice problem}

In this step of the evaluation methodology the generation and definition of alternatives takes place. Besides this, the selection of criteria, as well as the assessment of effects are considered. The assessment of relevant effects entails the changes in welfare positions of all stakeholders. Part of these effects can be measured in monetary terms, but part may have to be measured in other than monetary terms such as environmental effects, travel time, etc. Clearly, the identification of the effects of choice possibilities is not easy, but the valuation of these effects is quite a different issue, which also takes place in this step of the evaluation process. The result of this first step is the creation of a data set on the information architecture. This data set is still rudimentary and needs to be analysed more closely in the second step. 


\section{Step 2. Analysis of information}

In this stage of the evaluation process a more in-depth analysis of the data gathered takes place. Questions on the type of data to be examined (ordinal, cardinal, etc.), the completeness of the data set, the mutual relationships among the data, reduction of the data set without losing information and so forth, are addressed. Data classification methods like Discriminant Analysis, Principal Component Methods or Rough Set Analysis may meaningfully applied in this phase of the evaluation process (see for an overview of Rough Set Analysis Pawlak, 1991 and Slowinski, 1995).

The result of this step is the assembly of a structured information table (impact table) which forms the input for an evaluation method (or combination of methods).

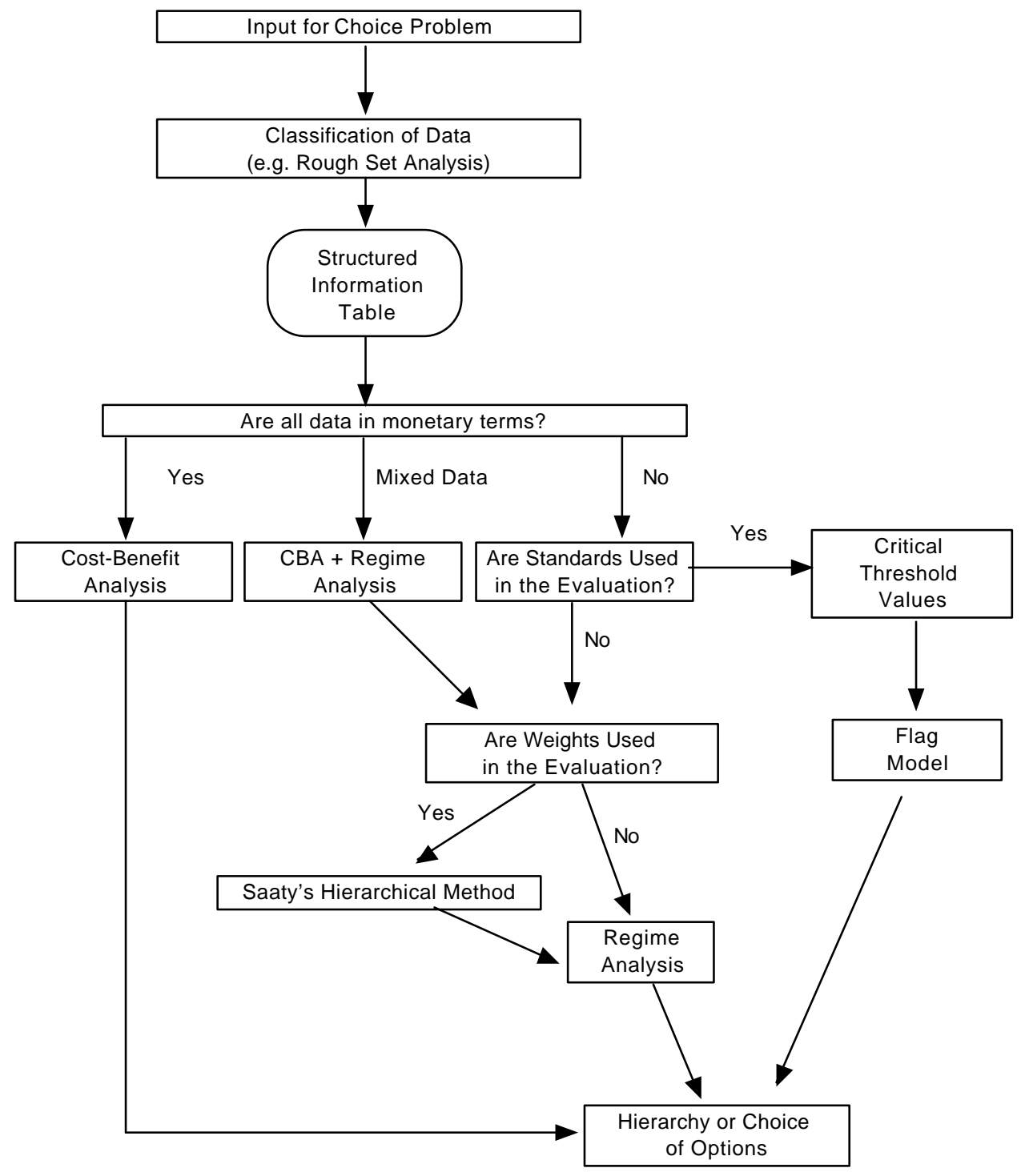

Figure 1. Steps in the Evaluation Methodology. 


\section{Step 3. Choice of appropriate evaluation method}

The methods included in an evaluation methodology differ according to their aim and characteristics in practical decision support situations, in particular in terms of their level of measurement, their classification, and the use of reference values. Although the methods considered do differ in many respects they have one common feature, viz. the aim to evaluate the pros and cons of a planned transport policy initiative or infrastructure investment. The choice of the appropriate method (or combination of methods) in any given transport policy context depends therefore on the features of the policy problem at hand, on the aims of the policy analysis, and on the underlying information base. The ultimately proposed and deployed evaluation methodology has to ensure compatibility and consistency between the evaluation method used and the actual transport problem to be tackled.

Clearly, this approach towards the selection of the class of multicriteria methods becomes more relevant if traditional evaluation methods, such as CBA, cannot be applied due to information shortages or specific requirements in a decision-support environment.

The following steps seem to be indispensable in the rational selection of an appropriate evaluation method (see Figure 1, Step 3):

1. If all effects are quantitative and in monetary terms, apply CBA;

2. If parts of the information are expressed in monetary terms and others in quantitative, nonmonetary or qualitative terms, apply CBA to this part of the data set. This can only be done if all requirements are met for this type of evaluation. After the application of CBA, the results should be combined with the remaining part of the data set by introducing the Cost-Benefit ratio's in the database. Apply next to this newly created data set (quantitative or a mixed quantitative-qualitative data set) a proper multicriteria method, notably Regime Analysis;

3. If effects are quantitative and/or qualitative, but not monetary in nature, and if no standards (or critical levels) are used in the evaluation process, then the application of Regime Analysis is in order. In the Regime Analysis Software there is also an option available to include weights in the evaluation process. This can be done by means of Saaty's Analytic Hierarchic Process method.

4. If standards or critical values are used in the evaluation process, one should resort to the Flag approach. The Flag Model evaluates the selected alternatives in relation to predefined standards.

\section{Step 4. Evaluation of alternatives; hierarchy or choice of options}

In this step the evaluation of alternatives takes place by means of the selected (combination of) evaluation method(s), weights or pre-defined standards. The final result will be a rank order of alternatives, a classification of these alternatives or a final selection.

In conclusion, the methods included in our evaluation methodology are based on the foundations of CBA, and form a decision-support complement to this type of analysis in a modern evaluation process. 


\section{The Evaluation Methods Used: A Description}

The designed methodology is based on a joint use of various multicriteria evaluation methods. The core of the methodology is formed by Regime Analysis, extended with complementary methods, viz. the Flag Model and Saaty's Analytic Hierarchic Process method. We will now describe the methods in some more detail. We will start with a presentation of the so-called Flag Model.

\subsection{The Flag Model}

The main purpose of the Flag Model is to analyse whether one or more policy alternatives can be classified as acceptable or not in the light of an a-priori set of constraints. The model does so by comparing impact values with a set of reference values (called Critical Threshold Values). The Flag Model has been designed to assess the degree to which competing alternatives fulfil pre-defined standards or normative statements in an evaluation process (see for applications of the Flag Model Nijkamp and Ouwersloot (1998) and Nijkamp and Vreeker (2000)). There are four important steps in applying the model:

- Identifying a set of measurable indicators;

- Assessing the impact of the alternatives on the above-mentioned indicators;

- Establishing a set of normative reference values (standards);

- Evaluation of the relevant alternatives.

The input of the Flag Model is formed by an impact matrix (structured information table) containing multi-dimensional information on a set of policy-relevant variables or criteria; this matrix contains the values that the indicators assume for each alternative considered. Therefore, the methodology requires the identification and definition of relevant indicators, which are suitable for further empirical treatment in the evaluation process.

The choice of indicators depends on the choice problem to be addressed; in general, the indicators should be in agreement with the nature of the choice issue under scrutiny and also consider the objectives to be taken into consideration. One significant threat always encountered when defining indicators is the likelihood that the number of indicators to be considered tends to grow limitless; and, to complicate matters, some indicators are encompassed within other indicators. In order to avoid the complication of a large number of indicators (which would be difficult to examine) and which often contain less relevant or unnecessary information, it may be a helpful approach to use a hierarchical approach based on a tree-like structure. Such an approach corresponds to the idea of aggregation and disaggregation of indicators that are deemed fundamental to the problem examined. For instance, a distinction can be made between macro, meso and micro indicators, or on the basis of relevant time or geographical scales. The indicators in the Flag Model have two formal attributes, class and type. There are normally three classes of indicators in the Flag Model, which correspond to the following dimensions: (1) environmental, (2) social, and (3) economic. The second attribute, type, relates to the fact that some indicators, e.g. accessibility to water, have high scores showing a preferable situation, whereas others, such as a pollution 
indicator, have low scores showing also a preferable situation. This difference, in terms of benefit or cost-criteria, is captured in the model under the attribute 'type of indicator'.

For each indicator in the Flag Model, preferably a critical threshold value (CTV) has to be defined. These values represent the reference system for judging alternatives. Since in many cases experts and decision-makers may have conflicting views on the precise level of the acceptable threshold values, a bandwidth of critical threshold values - by way of sensitivity analysis - can be used in the analysis. This bandwidth ranges from a maximum value $\left(\mathrm{CTV}_{\max }\right)$ to a minimum value $\left(\mathrm{CTV}_{\min }\right)$. This can be represented as follows:

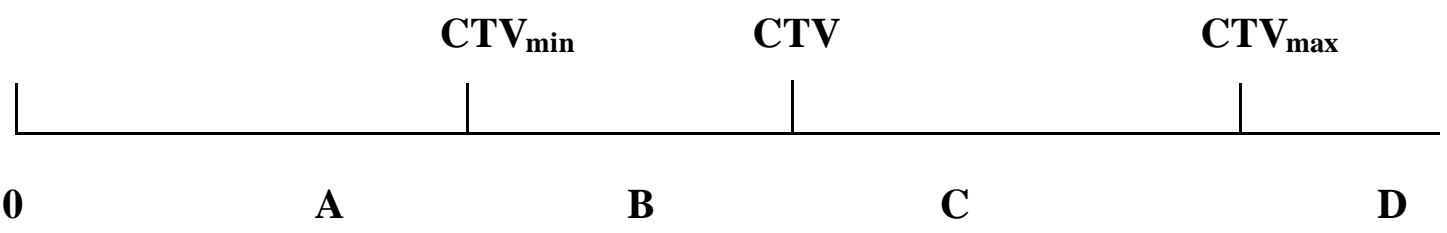

\begin{tabular}{||l|l|l||}
\hline Section A & Green & no reason for specific concern \\
\hline Section B & Yellow & be very alert \\
\hline Section $\mathbf{C}$ & Red & reverse trends \\
\hline Section D & Black & stop further growth \\
\hline
\end{tabular}

The assessment module of the Flag Model provides a number of instruments for the analysis of alternatives. This analysis can be carried out in two ways. The first option is the inspection of a single alternative. The second one is the comparison of choice options. In the first procedure we decide whether an alternative is acceptable or not. In the latter case of comparing two alternatives, we decide which alternative scores best. This last option may be interpreted as a basic form of multicriteria analysis.

The Flag Model can operate both as a classification procedure and as a visualisation method. In the former case - for example, in combination with Regime Analysis - the Flag Model can determine the acceptable alternatives; accordingly, the examined alternatives can then be ranked by means of Regime Analysis. In the latter case, we can utilise the Flag Model to visualise in an appealing way the results obtained, for example, from Regime Analysis or from an other set of classification or evaluation methods.

One of the major merits of the Flag Model is its potential for representation. There are three approaches to such a representation: a qualitative, a quantitative and a hybrid approach. The idea of having three possible options for result representation is based upon the necessity for the Flag Model and the accompanying software to be flexible to the requirements of its users. Rather than to be used as substitutions, the three modes of analysis are complementary to each other.

The qualitative approach only takes into account the colours of the flags. This entails flag counts and cross-tabulation. This approach merely displays in various insightful ways the results obtained from the evaluation. The quantitative approach defines the values of the standards that may be acceptable or not. To achieve such results, we need to standardise the indicator (values), because they refer to different aspects, which are next expressed by 
different measurement scales. Finally, the hybrid form regards the existence of both qualitative and quantitative aspects.

\subsection{Regime Analysis}

Multi-criteria analysis comprises various classes of decision-making approaches. The multiassessment method used in our methodology is Regime Analysis. Regime Analysis is a discrete multi-assessment method suitable to assess projects as well as policies. The strength of Regime Analysis is that it is able to cope with binary, ordinal, categorical and cardinal (ratio and interval scale) data, while the method is also able to use mixed data. This applies to both the effects and the weights in the evaluation of alternatives.

The fundamental framework of the method is based upon two kinds of input data: an impact matrix (structured information table) and a set of (politically determined) weights (Nijkamp et al, 1990 and Hinloopen et al, 1983). The impact matrix is composed of elements that measure the effect of each considered alternative in relation to each policy relevant criterion. The set of weights incorporates information concerning the relative importance of the criteria in the evaluation. In case there is no prioritisation of criteria in the evaluation process, all criteria will be assigned the same numerical weight value.

Regime Analysis is a discrete multicriteria method, and in particular, it is a generalised form of concordance analysis, based in essence on a generalisation of pairwise comparison methods. In order to gain a better understanding of Regime Analysis; let us reiterate the basic principles of concordance analysis.

Concordance analysis is an evaluation method in which the basic idea is to rank a set of alternatives by means of their pairwise comparisons in relation to the chosen criteria. We consider a choice problem where we have a set of alternatives $i$ and a set of criteria $\mathrm{k}$. We begin our analysis by comparing alternative $\mathrm{i}$ with alternative $\mathrm{k}$ in relation to all criteria. After having done this, we select all criteria for which alternative i performs better than, or is equal to, alternative k. This class of criteria we call a "concordance set". Similarly, we define the class of criteria for which alternative i performs worse than, or is equal to, alternative $\mathrm{k}$. This set of criteria is called a "discordance set".

We now need to rank the alternatives. In order to do so, we introduce the concordance index. The concordance index will be the sum of the weights that are related to the criteria for which $\mathrm{i}$ is better than $\mathrm{k}$. We call this sum $\mathrm{C}_{\mathrm{ik}}$. Then we calculate the concordance index for the same alternatives, but by considering the criteria for which $\mathrm{k}$ is better than i, i.e., $\mathrm{C}_{\mathrm{ki}}$.

After having calculated these two sums, we subtract these two values in order to obtain the net concordance index ${ }_{\mathrm{ik}}=\mathrm{C}_{\mathrm{ik}}-\mathrm{C}_{\mathrm{ki}}$.

Because in most cases we have only ordinal information about the weights (and no trade-offs), our interest is in the sign of the net concordance index ik. If the sign is positive, this will indicate that alternative $\mathrm{i}$ is more attractive than alternative $\mathrm{k}$; otherwise, the opposite holds.

We are now able to rank our alternatives. We note that due to the ordinal nature of the information in the indicator ik no information exists on to the size of the difference between the alternatives; it is only the sign of the indicator that matters. 
We may also solve the complicating situation that it may not be able to determine an unambiguous result, i.e. a complete ranking of alternatives, because of the problem of ambiguity in the sign of the index $\mu$. In order to solve this problem we introduce a performance indicator - as a semi-probability measure - $p_{i k}$ for the dominance of criteria $i$ with respect to criteria $\mathrm{k}$ as follows:

$p_{i j}=\operatorname{prob}\left(\mu_{i j}>0\right)$

Next, we define an aggregate probability measure, which represents the success (performance) score as follows:

$p_{i}=\frac{1}{I-1} \sum_{j \neq i} p_{i j}$

where $\mathrm{i}$ is the number of chosen alternatives.

The problem here is to assess the value of $\mathrm{p}_{\mathrm{ij}}$ and of $\mathrm{p}_{\mathrm{i}}$. The Regime Analysis then assumes a specific probability distribution of the set of feasible weights. This assumption is based upon the Laplace criterion in the case of decision-making under uncertainty.

In the case of a probability distribution of qualitative information, in principle, the use of stochastic analysis will suffice, which is consistent with an originally ordinal data set. This procedure helps to overcome the methodological problems we may encounter by applying a numerical operation on qualitative data.

From the viewpoint of numerical analysis, the Regime method identifies the feasible domain within which feasible values of the weights w must fall in order to be compatible with the condition imposed by their probability value. By means of a random generator, numerous values of the weights can be calculated. This allows us at the end to calculate the probability score (or success score) $p_{I}$ for each alternative i. We can then determine an unambiguous solution and rank the alternatives.

Regime Analysis is able to examine both quantitative and cardinal data. In case of choice problems with qualitative data, we first need to transform the qualitative data into cardinal data and then apply the Regime method. The Regime Software method is able to do so consistently ${ }^{1}$. Due to this necessity, Regime Analysis is classified as an indirect method for qualitative data. This is an important positive feature. When we apply the cardinalisation of qualitative data through indirect methods such as the Regime Analysis, we do not lose information like in direct methods. This is due to the fact that in the direct methods only the ordinal content of the available quantitative information is used.

\footnotetext{
${ }^{1}$ Regime analysis is included in the software package SAMIsoft, a deliverable of the EU project SAMI.
} 


\subsection{Saaty's Analytical Hierarchical Process method (AHP)}

The core of Saaty's method is an ordinal pair-wise comparison of all criteria. In other words, it addresses in particular preference statements. Per pair of criteria the decision-maker is asked to which degree a criterion is of more importance than the other. By means of these comparisons the method defines the relative position of one criterion in relation to all other criteria. By using an eigenvalue matrix technique, quantitative weights can be assigned to the criteria.

The Saaty method (Analytic Hierarchy Process method, AHP) has been developed by Thomas Lorie Saaty in the 1970s (Saaty, 1988). This method is based upon three important components:

1. The hierarchical articulation of the elements of the decision problem;

2. The identification of the priority scheme;

3. A check on the logic consistency of the priority expressed.

The procedure is conducted in different steps. The first steps consist of the definition of the problem and of the identification of the criteria in a hierarchy of five levels:

- Level 1: general objective(s)

- Level 2: criteria

- Level 3: sub-criteria

- Level 4: indicators

- Level 5: index

After defining the hierarchy articulation of the elements, the second step consists of assessing the value of the weights related to each criterion through a pairwise comparison between the elements.

The SAATY method employs a semantic 9-point scale (Table 1) for the assignment of priority values. This scale relates numbers to judgements, which express the possible results of the comparison in qualitative terms. In this way, different elements can be weighted with a homogeneous measurement scale.

Table 1. Semantic scale of Saaty.

\begin{tabular}{|l|l|}
\hline Value & Definition \\
\hline 1 & Equal importance \\
\hline 3 & Moderate importance \\
\hline 5 & Strong importance \\
\hline 7 & Very strong importance \\
\hline 9 & Extreme importance \\
\hline $2,4,6,8$ & Intermediate value \\
\hline
\end{tabular}


Through this method, the weight assigned to each single criterion reflects the importance which every party /agent /group involved in the project attaches to the objectives. In addition, the method verifies the fit between the components of the weight vector and the original judgements. From the pairwise comparison a 'comparison matrix' is derived out of which, through the eigenvector approach, it is possible to calculate the weight vector to be used for a subsequent evaluation and investigation. Finally, the method is able to check the consistency of the matrix through the calculation of the eigenvalues.

\section{Application of the Evaluation Methodology and Methods}

Multicriteria methods have been applied to a great variety of environmental and land use problems. We will offer here an illustration from the aviation sector in The Netherlands.

In the past decades various stakeholders in The Netherlands discussed the problems concerning the development of the Dutch airports. These discussions were often focussed on environmental effects of airports (e.g. nuisance). The above-mentioned discussions and problems are not solely related to the national airport Schiphol Amsterdam, but also to the regional airports in The Netherlands.

While in the past discussions and decisions on the development of airports were often dominated by economic arguments favouring the extension of the airport concerned, nowadays an assessment of all related (direct and indirect) effects takes place.

In this part of the paper, we illustrate the application of the evaluation methodology developed above by means of a case study on conflicting plans (and policy views) for airport expansion in the Maastricht area in the Southern part of the Netherlands.

First, we will describe the main characteristics of the problem at hand with the aim to illustrate its complexity and to identify the necessary information that plays a role in the evaluation and choice of alternatives. Next, we will apply Regime Analysis and the Flag Model in order to evaluate the choice alternatives.

\subsection{Maastricht Aachen Airport (MAA): a short description}

In 1945, the U.S. liberation army erected a military airport in the Maastricht area in The Southern part of the Netherlands. In the subsequent decades this small military airport became a regional airport, which is nowadays named Maastricht Aachen Airport.

At the moment most aircraft movements from Maastricht Aachen Airport are related to passenger traffic. Each year, around 350.000 passengers use the airport as departure point or final destination. Airfreight handling at the airport is limited to 33.000 ton each year, since the landing strip is not long enough; it can only accommodate small freighter aircraft. Besides this, the strip is only opened for a limited period during the day (e.g., no flights during the night). This leads to a diminishing comparative advantage and a feeble position on the airfreight market with respect to other European (regional) airports.

To cope with these problems and to improve the profitability of the airport, four alternative development scenarios were designed as possible policy strategies. The four scenarios differ very much in nature and aims. The scenarios are heterogeneous and designed as extreme points of a so-called feasibility spectrum. The first scenario Business as Usual is 
designed as a reference scenario and refers to the situation where no changes in current trends and policies occur. The second scenario MAA serving as passenger airport is aimed at analysing the impacts of changes in the logistics of the airport. MAA serving the "Euregio" is constructed to evaluate the impacts of land use changes in the region. The last scenario Tradable Permits is dominated by changes in the institutional setting of the airport. In this scenario changes occur in the legislation regarding the emission of $\mathrm{CO}_{2}$ in The Netherlands. This scenario differs in nature somewhat from the previous ones, but has been mentioned several times in recent discussions. It can also be applied in combination with the three preceding ones. These four options will now concisely be discussed.

\section{Scenario 1: Business as Usual}

This scenario serves as a reference scenario. Current trends are used to make predictions about the future. The main purpose of this scenario is to evaluate the situation where there are no changes in current trends and policies. This scenario can be summarised as follows:

1. A further decrease of aircargo handling at MAA; the decrease will be 5.000 tons a year;

2. A stabilisation of passengers traffic at a stable level of 350.000 passengers a year;

3. A substitution of slots and aircraft movements originally designated for airfreight services toward passenger transport.

\section{Scenario 2: MAA serves as a Passenger Airport}

In this choice option MAA will concentrate on the passengers market as a source of profit. Although freight handling will still be present at MAA, it is not recognised as the "core business". In this scenario a new runway (the East-West strip) is constructed in order to accommodate larger aircrafts at MAA. Besides this, the Dutch National Aviation School will leave the airport. This gives the opportunity to extend the number passengers flights with 55.000 aircraft movements. This scenario can be summarised as follows:

1. Construction of a new runway;

2. Outplacement of the Dutch National Aviation School to another airport, thus leaving room for 55.000 additional aircraft movements;

3. No further expansion of freight handling at MAA.

\section{Scenario 3: MAA as an "Euregio" Airport}

In this third scenario MAA will serve as the main regional airport in the Euregio (see Figure 2). In this role MAA has to attract passengers from regions nearby in Belgium and Germany. Besides this, MAA has to play a major role in the freight market for the "Euregio". Therefore, the construction of a new (East-West) runway is necessary. This runway should be larger than the one in scenario 2. To summarise:

1. Construction of a new large runway at MAA to accommodate larger passenger flows and freight aircraft;

2. Establishment of an open night regime, so that starts and landings are allowed for 24 hours a day. 


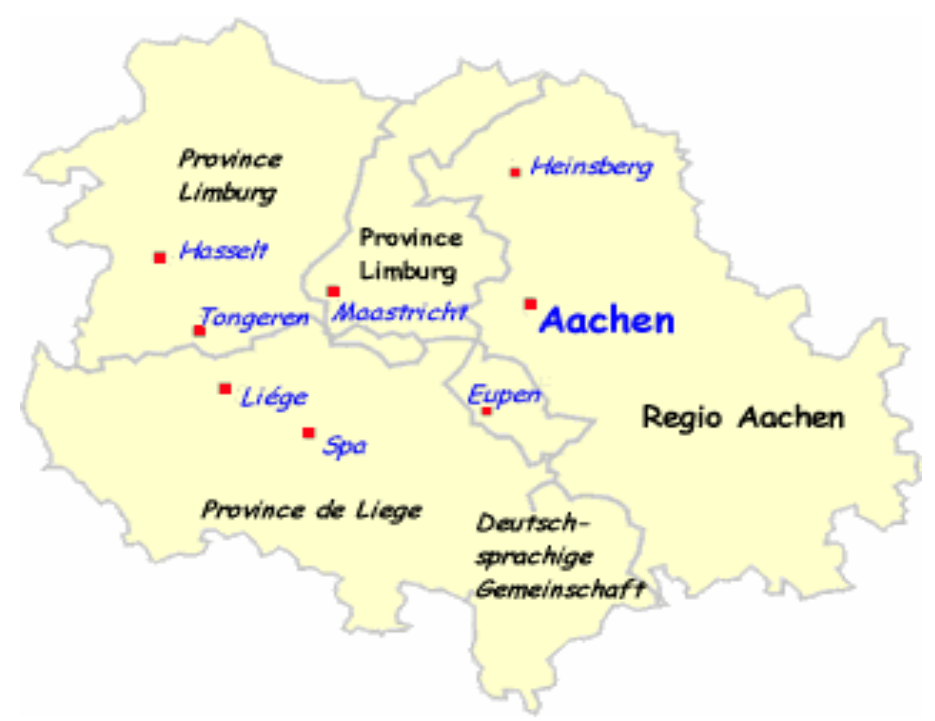

Figure 2. The "Euregio".

\section{Scenario 4: Tradable Permits}

In this scenarios permits concerning the emission of $\mathrm{CO}_{2}$ are traded among the regional airports in the Netherlands. The national number of permits is fixed. In such a case airports can only expand their activities, if they buy permits from other regional airports. In this scenario MAA is a buyer on the market of permits. This means in concise terms:

1. MAA is a buyer on the market of $\mathrm{CO}_{2}$ permits;

2. MAA is not capable or allowed to expand its activities without buying additional permits;

3. Schiphol Amsterdam, the national airport of the Netherlands, is not a player on the market.

In the next section of the paper we will pay attention to the criteria and indicators which are used to measure the effects exerted by the above-mentioned scenarios on the Maastricht region. The scores the scenarios assume on the indicators form an important input for our Flag Model and the Regime Analysis, and hence in the evaluation methodology.

\subsection{Hierarchical definition of criteria and assembling the impact matrix}

The choice process of a transport infrastructure project against the background of the concept of sustainability should be based upon a broad set of criteria which allow for the simultaneous consideration of a project impact from different viewpoints, notably economic, social and environmental. The corollary of adopting this view is that an optimisation of logistic functionality will not result in an excessive cost for the environment and for society (i.e., a burden higher than the system's carrying capacity). Such a carrying capacity is not solely related to the infrastructure's physical capacity, but also to the carrying capacity of the environment. The latter concept is defined through the inclusion of pollution (of water, air and soil, in visual and acoustic forms, etc.) of the territory's capability of accommodating new infrastructure and of the society's carrying capacity, expressed e.g. in terms of safety levels. 
Main attention in our case study is devoted to the attainment of the best possible solution, viz. one that is functionally effective and at the same time compatible with constraints imposed by relevant environmental and social circumstances. The evaluation criteria used in this assessment are defined in relation to the concept of sustainability, notably through the identification of three main classes of indicators: economy, accessibility and environment.

For each of these classes a list of indicators has been specified. The latter ones stem from a thorough analysis of site-specific problems and allow us to evaluate each alternative in respect to pre-defined objectives. In Table 2 the indicators are summarised according to their main types (economic, social, environment). At the right-hand side of Table 2, three columns are added those show the specified Critical Threshold Values for each indicator; these Critical Threshold Values are used as input for the Flag Model.

The various data referring to the sub-criteria are in our case study expressed and measured on an ordinal scale, through which numerical values on a 9-point scale (where the highest value represents the best score) were assigned to the various effects. We can now summarise the consequences each distinct alternative has by means of an impact matrix (see Table 3). In this matrix the pre-defined criteria are linked to the alternatives by means of the values each alternative scores on the pre-defined criteria.

Table 2. Criteria used in the airport evaluation process.

\begin{tabular}{|c|c|c|c|c|c|c|}
\hline Main Criteria & Sub-criteria & Type & Scale & $\begin{array}{l}\text { CTV } \\
\min \end{array}$ & CTV & $\begin{array}{l}\text { CTV } \\
\max \end{array}$ \\
\hline \multirow[t]{8}{*}{ Economic } & Economic Benefits for the Region & Benefit & Qualitative & 3 & 5 & 7 \\
\hline & $\begin{array}{l}\text { Employment in Sector Transport and } \\
\text { Logistics }\end{array}$ & Benefit & Qualitative & 3 & 5 & 7 \\
\hline & $\begin{array}{l}\text { Employment in Sector Finance and } \\
\text { Business to Business }\end{array}$ & Benefit & Qualitative & 3 & 5 & 7 \\
\hline & $\begin{array}{l}\text { Employment in Sector Tourism and } \\
\text { recreation }\end{array}$ & Benefit & Qualitative & 3 & 5 & 7 \\
\hline & $\begin{array}{l}\text { Development and Supply of Industrial } \\
\text { Sites }\end{array}$ & Benefit & Qualitative & 3 & 5 & 7 \\
\hline & Infrastructure & Benefit & Qualitative & 3 & 5 & 7 \\
\hline & Business Traffic & Benefit & Qualitative & 3 & 5 & 7 \\
\hline & Supply of Skilled Jobs & Benefit & Qualitative & 3 & 5 & 7 \\
\hline \multirow[t]{6}{*}{ Social } & Nuisance & Benefit & Qualitative & 3 & 5 & 7 \\
\hline & Safety & Benefit & Qualitative & 3 & 5 & 7 \\
\hline & Health & Benefit & Qualitative & 3 & 5 & 7 \\
\hline & Recreational Traffic & Benefit & Qualitative & 3 & 5 & 7 \\
\hline & Total Income & Benefit & Qualitative & 3 & 5 & 7 \\
\hline & Residential Areas & Benefit & Qualitative & 3 & 5 & 7 \\
\hline \multirow[t]{6}{*}{ Environmental } & Natural Conservation Areas & Benefit & Qualitative & 3 & 5 & 7 \\
\hline & Disturbance of Fauna's Habitat & Benefit & Qualitative & 3 & 5 & 7 \\
\hline & Air Quality & Benefit & Qualitative & 3 & 5 & 7 \\
\hline & Water Quality & Benefit & Qualitative & 3 & 5 & 7 \\
\hline & Soil Quality & Benefit & Qualitative & 3 & 5 & 7 \\
\hline & Biodiversity & Benefit & Qualitative & 3 & 5 & 7 \\
\hline
\end{tabular}


Table 3. The impact matrix for alternative airport expansion plans.

\begin{tabular}{|c|c|c|c|c|c|}
\hline & Criterion & A & B & $\mathrm{C}$ & $\mathrm{D}$ \\
\hline \multirow{8}{*}{ 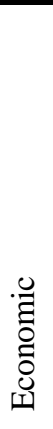 } & Economic Benefits for the Region (+) & 4 & 8 & 9 & 6 \\
\hline & Employment in Sector Transport and Logistics (+) & 4 & 5 & 8 & 6 \\
\hline & Employment in Sector Finance and Business to Business (+) & 5 & 9 & 7 & 6 \\
\hline & Employment in Sector Tourism and recreation $(+)$ & 6 & 5 & 1 & 3 \\
\hline & Development and Supply of Industrial Sites (+) & 5 & 3 & 1 & 6 \\
\hline & Infrastructure (+) & 5 & 8 & 9 & 6 \\
\hline & Business Traffic $(+)$ & 6 & 9 & 8 & 6 \\
\hline & Supply of Skilled Jobs (+) & 4 & 7 & 9 & 6 \\
\hline \multirow{6}{*}{ 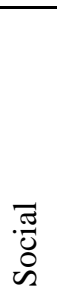 } & Nuisance (+) & 5 & 8 & 5 & 3 \\
\hline & Safety (+) & 5 & 7 & 2 & 3 \\
\hline & Health $(+)$ & 5 & 6 & 5 & 3 \\
\hline & Recreational Traffic (+) & 6 & 9 & 9 & 7 \\
\hline & Total Income (+) & 4 & 6 & 7 & 6 \\
\hline & Residential Areas (+) & 5 & 5 & 2 & 5 \\
\hline \multirow{6}{*}{ 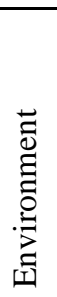 } & Natural Conservation Areas (+) & 5 & 4 & 1 & 3 \\
\hline & Disturbance of Fauna's Habitat (+) & 5 & 8 & 1 & 3 \\
\hline & Air Quality (+) & 4 & 6 & 1 & 4 \\
\hline & Water Quality (+) & 4 & 5 & 2 & 4 \\
\hline & Soil Quality (+) & 4 & 3 & 2 & 4 \\
\hline & Biodiversity (+) & 4 & 5 & 2 & 4 \\
\hline
\end{tabular}

\subsection{Regime Analysis; obtaining a rank order of alternatives}

The Regime Method described in Section 3.2 allows us to analyse an impact matrix (Table 3) containing mixed data and a weight vector in order to calculate a rank order of alternatives. The weights may be assumed to be equal, but also alternative weight compositions can be handled by means of a sensitivity analysis.

The software used to evaluate all alternatives in this case study (SAMIsoft) considers all the scores as benefit criteria; this means that the higher a alternative scores on a criteria the better. Therefore, our impact matrix (Table 3) is constructed of only benefit criteria and cost criteria were transformed into benefit criteria.

In our case study research, the Regime Analysis was conducted in two steps. First, a Regime Analysis was performed on each of the main classes (Economic, Social and Environment). By means of the values each alternative scores on the relevant sub-criteria, the scores for each main class were determined. These results are presented by the intermediate results in Table 4. In the second step the intermediate results formed the input, together with a uniform weight vector, for a final Regime Analysis. The results of this analysis are presented in Table 4 and Figure 3. 
Table 4. Rank order of alternatives (weights of criteria are equal).

\begin{tabular}{|c|c|c|c|c|c|c|c|c|c|c|c|}
\hline \multirow{2}{*}{\begin{tabular}{|l|} 
Criteria \\
Economic
\end{tabular}} & & \multicolumn{3}{|c|}{ Intermediate results } & & & \multicolumn{3}{|l|}{$\begin{array}{l}\text { Final } \\
\text { results }\end{array}$} & & \\
\hline & & $\mathrm{A}$ & $\mathrm{B}$ & $\mathrm{C}$ & $D$ & & & & & & \\
\hline & & 0 & 0.82 & 0.83 & 0.34 & & & & & & \\
\hline Social & $\rightarrow$ & A & B & C & D & & A & B & & $\mathrm{C}$ & $D$ \\
\hline & & 0.42 & 1 & 0.48 & 0.1 & 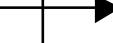 & 0.34 & & 0.94 & 0.61 & 0.11 \\
\hline Environment & $\rightarrow$ & A & B & C & D & & & & & & \\
\hline & & 0.69 & 0.97 & 0 & 0.33 & & & & & & \\
\hline
\end{tabular}

The intermediate results show that alternatives B and C (Passenger airport and "Euregio") have the highest scores on the economic indicators. Besides this, alternative $\mathrm{B}$ scores also very well on the social and environmental indicators. It will be no surprise that this scenario is the most favoured one in the final Regime Analysis. Accordingly, the final rank order is:

1. Scenario 2: Passenger Airport.

2. Scenario 3: MAA serving the "Euregio".

3. Scenario 1: Business as Usual.

4. Scenario 4: Tradable Permits.

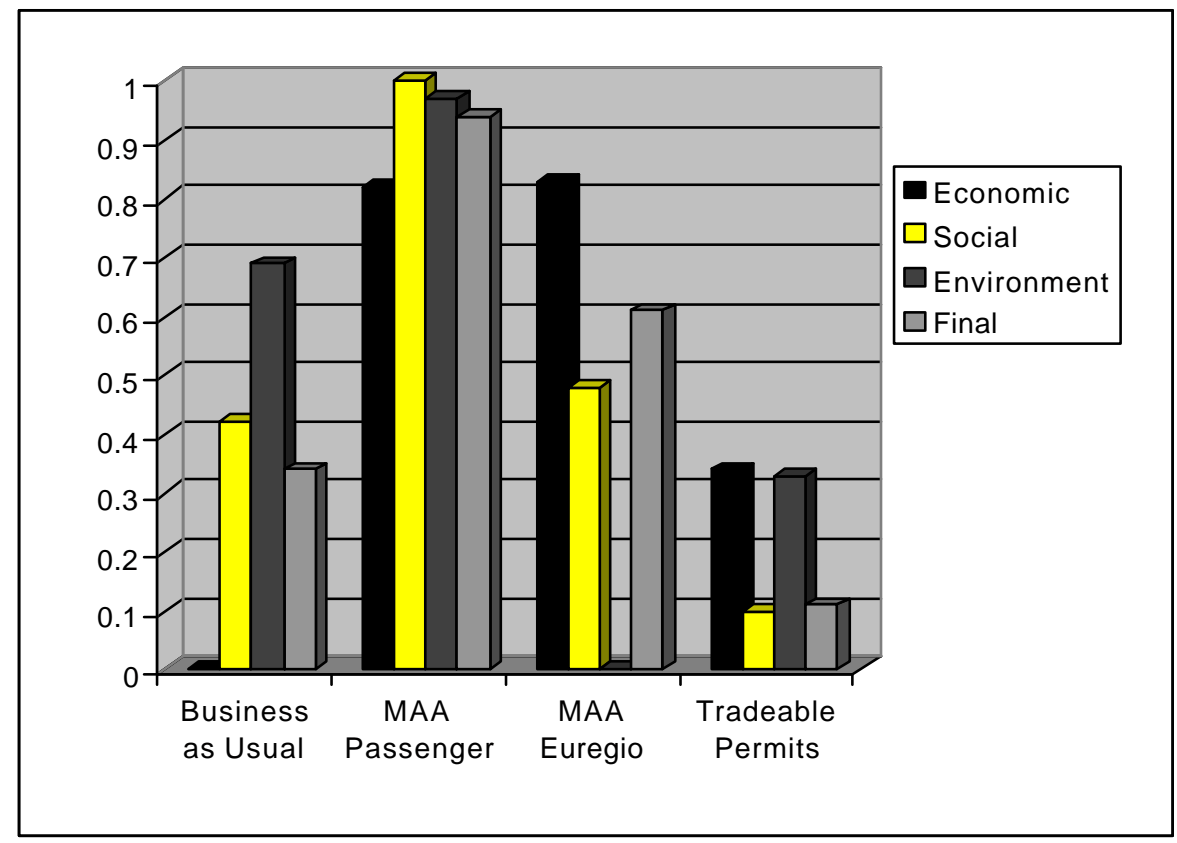

Figure 3. Results of the Regime Analysis.

\subsection{Acceptability of alternatives; application of the Flag Model}

In this subsection we will illustrate the application of the Flag Model to check the acceptability of the four alternatives, in this case from the viewpoint of the sustainability concept, with regard to a set of reference values (Critical Threshold Values). This analysis is carried out by means of the Flag Model that is included in the multicriteria evaluation software package SAMIsoft. 
The Flag Model needs two types of input: an impact matrix (see Table 3) and a set of Critical Threshold Values. The impact matrix is formed by the values that the indicators assume for each alternative considered. Besides the construction of the impact matrix, for each indicator a Critical Threshold Value has to be defined. These values represent the reference system for judging the alternatives.

The use of Critical Threshold Values is related to a normative view on the concept of sustainability (see Nijkamp and Ouwersloot, 1998 and Nijkamp and Vreeker, 2000, where more attention is paid to the question how sustainability can be identified as a normative orientation for policy). In other words, the question is: is it possible to define a set of reference values or Critical Threshold Values (limits, standards or norms) to trace and evaluate the impacts of policies and infrastructure projects on the environment and society?

In this context, the notion of carrying capacity is of importance, as it indicates the maximum use of environmental resources that is still compatible with an ecologically sustainable economic development. This means that a Critical Threshold Value cannot be exceeded without causing irreversible and unacceptable damage or costs to the environment or society.

Table 3 and the list of Critical Threshold Values in Table 2 form the input for the Flag Model. Table 5 shows the results of the analysis by means of the frequency of flags per alternative in respect to each relevant main class of criteria. In Figures 4, 5, 6 and 7 the frequencies of flags are presented by means of charts.

Table 5. Frequencies of flags.

\begin{tabular}{|l|l|l|l|l|l|l|l|l|l|l|l|l|l|l|l|l|l|}
\hline & \multicolumn{3}{|l|}{$\begin{array}{l}\text { Business as } \\
\text { Usual }\end{array}$} & \multicolumn{4}{l|}{$\begin{array}{l}\text { MAA } \\
\text { Passenger }\end{array}$} & \multicolumn{4}{l|}{$\begin{array}{l}\text { MAA } \\
\text { Euregio }\end{array}$} \\
\hline & B & R & Y & G & B & R & Y & G & B & R & Y & G & B & R & Y & G \\
\hline Economic & 0 & 3 & 5 & 0 & 0 & 1 & 2 & 5 & 2 & 0 & 0 & 6 & 0 & 6 & 0 & 0 \\
\hline Social & 0 & 1 & 5 & 0 & 0 & 0 & 3 & 3 & 2 & 0 & 2 & 2 & 0 & 1 & 7 & 0 \\
\hline $\begin{array}{l}\text { Environ- } \\
\text { mental }\end{array}$ & 0 & 4 & 2 & 0 & 0 & 2 & 3 & 1 & 6 & 0 & 0 & 0 & 0 & 3 & 2 & 1 \\
\hline
\end{tabular}

Our investigation of the results in Table 5 and Figures 4, 5, 6 and 7 shows that Scenario 2 MAA Passenger Airport is generally most acceptable/sustainable; it has in fact 9 green and 8 yellow flags. Most of these flags are scored on the economic and social indicators. This scenario has however, some negative effects on some environmental indictors; three of them are even labelled red. Although the third scenario "MAA serving the "Euregio" has 8 green and 2 yellow flags, it has an tremendous negative impact on the environment in the region, as is shown by the 6 black flags. The Tradable Permits scenario is not an option, since it is not economically viable, according to the 6 Red flags on the economic indicators. The impacts on the social indicators are positive. If we take a close look at the Business as Usual scenario, we see that this will not improve the development of MAA. In the long term it may be expected 
that the economic and environmental consequences of current trends and policies become more negative.

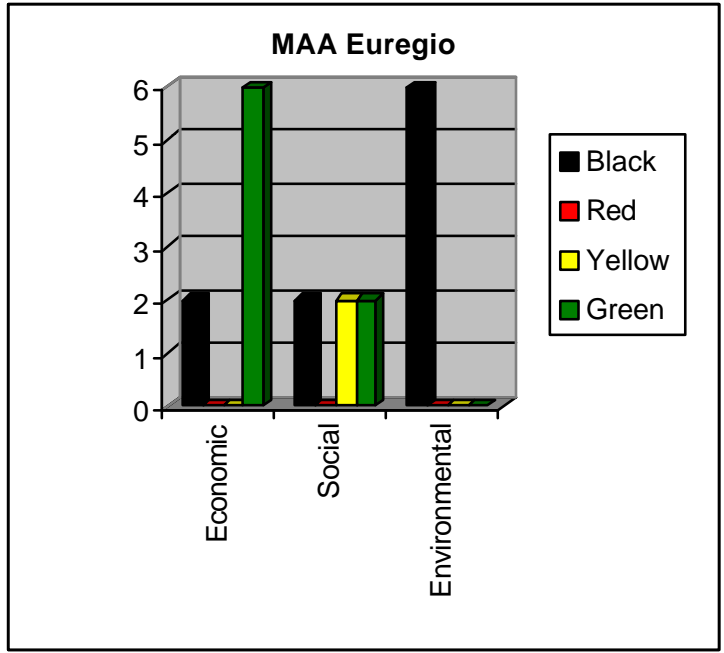

Figure 4. Flag frequencies

for Business as Usual.

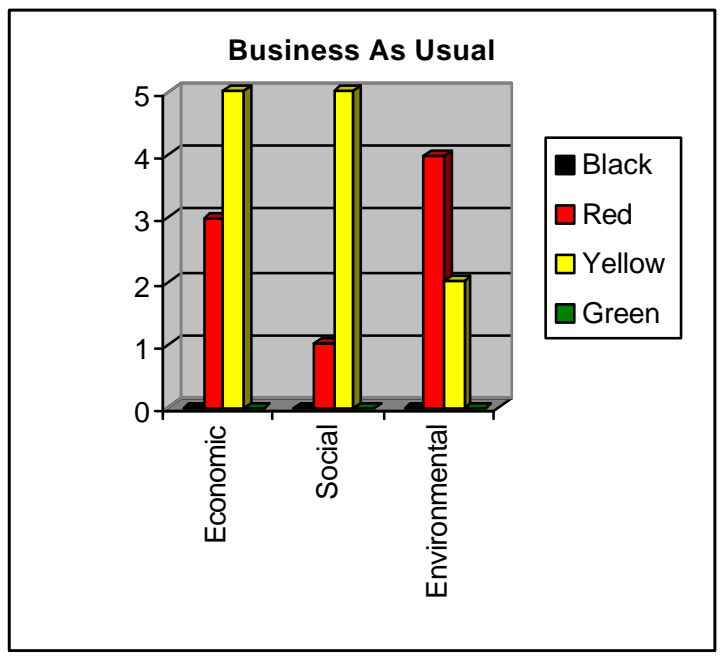

Figure 6. Flag Frequencies

for MAA Euregio.

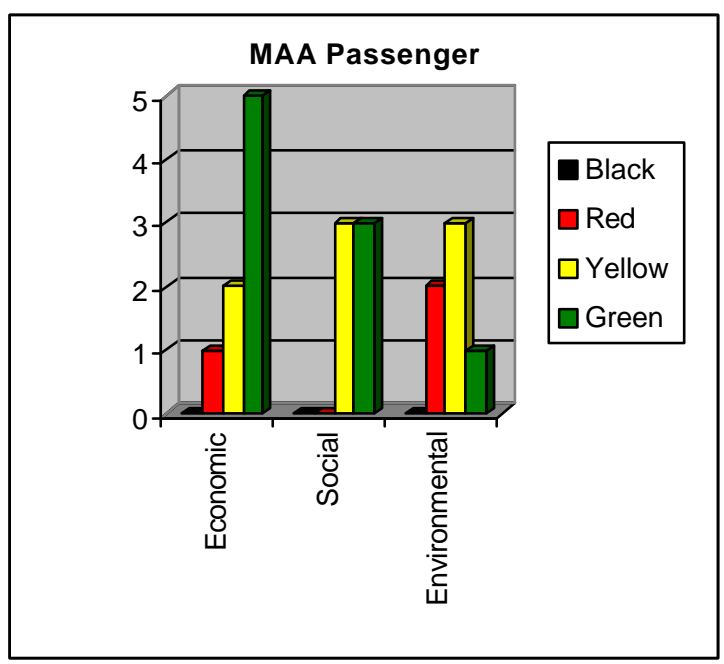

Figure 5. Flag frequencies

for MAA as Passenger Airport.

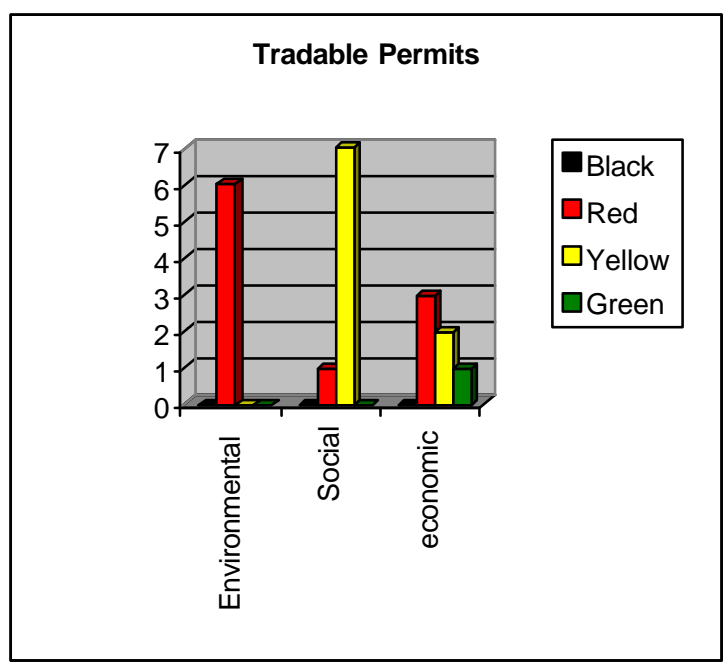

Figure 7. Flag Frequencies

for Tradable Permits.

\section{Some Reflections}

The aim of this paper is to offer decision-makers a methodology and a set of techniques in order to analyse the acceptability and priority of choice possibilities in the case of qualitative or mixed data on either effects of choices or policy priorities, or both. Three complementary evaluation methods have been proposed.

The application of the methods has led to the identification of the best possible ranking for each alternative as well as the degree of acceptability of each alternative with respect to a predefined set of critical threshold values. The results turned out to be plausible; they may perhaps not always coincide with prevailing political wisdom, but offer on the other hand a platform for a structured debate. 
In conclusion, the application of the multicriteria methods points out that these are very useful tools to deal with conflicts in a decision-making process. Three critical points deserve thorough attention. First, the methodology and accompanying software allows the decisionmaker to analyse conflicting choices and the degree of conflict among various policy objectives. Second, the methodology offers the decision-maker also the possibility to take into account the preferences of policy makers and stakeholders in a decision-making process, as well as to measure the impacts of these viewpoints. Finally, the use of critical threshold values provides the decision-maker with an operational framework for environmental sustainability analysis on a given site or in a given area.

\section{References}

De Brucker, K., Ontwikkeling Van Een Eclectisch Evaluatie-Instrument Voor De SociaalEconomische Evaluatie Van Complexe Investeringsprojecten, Met Een Toepassing Op Het Project Seine-Scheldeverbinding, phd thesis, Universiteit Antwerpen, 2000.

Fujita, M., P. Krugman, and A.J. Venables, The Spatial Economy, MIT Press, Cambridge, Massachusetts, 1999.

Hinloopen, E., P. Nijkamp and P. Rietveld, Qualitative Discrete Multiple Criteria Choice Models, Regional Planning, Regional Science and Urban Economics, pp. 77-102, 1983.

Layard, R., (ed.), Cost-Benefit Analysis, Penguin Books, England, 1997.

Mishan, E.J., Cost-Benefit Analysis, Allen \& Unwin, London, 1971.

Nijkamp, P., P. Rietveld and H. Voogd, Multicriteria Analysis for Physical Planning, Elsevier, Amsterdam, 1990.

Nijkamp, P., and E. Blaas, Impact Assesment and Evaluation in Transport Planning, Kluwer, Dordrecht, 1996.

Nijkamp, P., and H. Ouwersloot, A Decision Support System For Regional Sustainable Development. In: van den Bergh, J.C.J.M., Hofkes, M.W. (eds.), The Flag Model Theory and Implementation of Sustainable Development. Kluwer, Dordrecht, 1998.

Nijkamp, P., and R. Vreeker, Sustainability Assessment of Development Scenarios: Methodology and Application to Thailand, Ecological Economics 33, 7-27, 2000.

Pawlak, Z., Rough Sets, Kluwer, Dordrecht, 1991.

Pelt, M.J.F. van, Ecological Sustainability and Project Appraisal, Aldershot, Avebury, 1994. 
Rietveld, P., and F.R. Bruinsma, Transport Systems, Economic Change and Policy Analysis, Vrije Universiteit, Amsterdam, 1999.

Rietveld, P. and J. Rouwendal, Welvaartsaspecten Bij de Evaluatie Van Infrastructuurprojecten, Ministerie van Verkeer en Waterstaat, Den Haag, 2000.

Rietveld, P., Afwegingskader voor Beleid in Verkeer en Vervoer, Vrije Universiteit Amsterdam, Amsterdam, 2000.

Saaty, T.L., Decision Making for Leaders, Rws Publication, Pittsburgh, 1988.

SAMI, Strategic Assessment Methodology for the Interaction of CTP-Instruments, Deliverable 2: Review of Strategic Assessment Tool and Methods, DG7 Transport Research (Strategic), European Union, Fourth Framework Programme, 1998.

Slowinski, R., Intelligent Decision Support, Kluwer, Dordrecht, 1995. 